\title{
Syntax-Pragmatics Interface: Mandarin Chinese Wh-the-hell and Point-of-View Operator
}

\author{
Chao-Ting Tim Chou
}

\begin{abstract}
Based on previously unnoted data concerning wh-the-hell attitude-bearing questions in Mandarin Chinese, I argue that integrating the pragmatic notion "point of view" into the syntactic computation enables us to capture certain properties of wh-the-hell questions in Mandarin Chinese in a systematic and illuminating way. The two central phenomena analyzed are (1) causal zenme 'how come' is not compatible with daodi 'the-hell' in Chinese, and (2) in Chinese wh-the-hell questions, when daodi 'the-hell' takes matrix scope while staying overtly in the embedded clause, the person feature of the matrix subject cannot be third person. I argue that explaining these phenomena depends on recognizing the logophoricity of the negative attitudes carried by daodi and causal zenme. The valuation relation that I postulate between the Point-of-View operator and an unvalued Point-of-View feature of daodi and causal zenme not only explains these data but also formally captures certain properties of the Chinese logophor ziji (cf. Huang \& Liu 2001).
\end{abstract}

\section{Introduction}

We undertake the study of wh-the-hell questions in Mandarin Chinese (MC) to explore the territory of the syntax-pragmatics interface in this language. There are several properties of the MC wh-the-hell questions worth mentioning. First, the wh-the-hell question in $\mathrm{MC}$ is constructed by the wh-question operator, the attitudinal adverb daodi 'the-hell' and the wh-associate, as in (1). Unlike their English counterparts, ${ }^{1}$ in overt syntax, daodi 'the-hell' and its $w h$-associate do not need to form a constituent and both of them stay in situ, as exemplified by (2).

(1) $\mathrm{Q}_{\mathrm{wh}}$..daodi...wh

\section{(2) Ta daodi xihuan shenme? \\ he THE-HELL like what \\ 'What the hell does he like?'}

Second, as noted by Kuo (1996) and Huang \& Ochi (2004), in overt syntax, daodi 'the-hell' must occur in the c-command domain of the question operator in Spec,CP as

This article is a substantial revision of my Master's thesis completed at National Chiao Tung University in Taiwan. I am thankful to Luther Liu for giving me the inspiration to work on this topic in his syntax seminar in 2005. I am deeply indebted to Acrisio Pires and Samuel David Epstein for their insightful comments and continuing encouragement. I would also like to thank three anonymous Syntax reviewers, whose careful and valuable comments and suggestions greatly helped me with the revision of this paper. Any errors are entirely my own responsibility.

${ }^{1}$ The wh-the-hell expression in English must occur as a (continuous) constituent that obligatorily moves overtly (see Huang \& Ochi 2004:1-2):

(i) a. *What did you buy the hell?

b. *Who bought what the hell? 


\section{Chao-Ting Tim Chou}

shown by the contrast in (3), and the wh-associate (shei 'who') must be c-commanded by daodi as evidenced by (4).

(3) a. Ta xiang-zhidao $\left[\mathbf{Q}_{\mathbf{w h}}\right.$ ni daodi xihuan shei]. he wonder you THE-HELL like who

'He wonders who the hell you like.'

b. *Ta daodi xiang-zhidao $\left[\mathbf{Q}_{\mathbf{w h}}\right.$ ni xihuan shei].

(4) a. Ta xiang-zhidao $\left[\mathbf{Q}_{\mathbf{w h}}\right.$ daodi shei mei lai shang ke]. he wonder THE-HELL who not come attend class

'He wonders who the hell did not come to class.'

b. *Ta xiang-zhidao $\left[\mathbf{Q}_{\mathbf{w h}}\right.$ shei daodi mei lai shang ke].

Example (3b) is ungrammatical because daodi is not in the interrogative complement clause subcategorized by xiang-zhidao 'wonder', and (4b) is ill-formed because the wh-associate shei 'who' is not c-commanded by daodi even though the question operator c-commands daodi. Therefore, there exist two constraints: the question operator needs to c-command daodi, and daodi has to c-command the wh-associate, forming a serial c-command relationship.

Third, Huang, Li \& Li (2009:241) note that daodi can take matrix scope while staying overtly in the embedded clause as exemplified by (5). ${ }^{2,3}$

(5) $\mathrm{Ni}$ renwei [Lisi daodi xihuan shei]?

you think Lisi THE-HELL like who

'Who the hell do you think Lisi likes?'

Huang \& Ochi (2004:6) provide an illuminating summary of the structure of the wh-the-hell questions in MC. There are two kinds of dependencies in a MC wh-the-hell question as represented in (6): one between the null wh-question operator at Spec,CP and the attitudinal adverb daodi (dependency A), and the other between daodi and the wh-associate (dependency B). These three key elements must form a successive c-command relation as exemplified by (3) and (4). Dependency A exhibits island sensitivity due to daodi's covert adverbial movement, observed by Kuo (1996), ${ }^{4}$ and dependency $\mathrm{B}$ indicates that the wh-associate can occur in an island only if it is an

${ }^{2}$ By matrix scope, they mean that the negative attitude expressed by daodi covers the matrix sentence, indicating the attitude of the external speaker of the entire utterance.

${ }^{3}$ The example cited by Huang et al. (2009) to demonstrate this embeddability property of daodi is (i), but as I will show in the next section, the person feature of the matrix subject cannot be third person when daodi occurs in the embedded clause of a direct question. Daodi needs to occur in the matrix clause to make (i) grammatical as in (ii).

(i) *Lisi shuo [ta daodi shenme shihou hui jia]?

Lisi say he THE-HELL what time go home

'When the hell did Lisi say that he will go home?'

(ii) Lisi daodi shuo [ta shenme shihou hui jia]?

4 The island sensitivity of the distribution of daodi is not the focus of the current paper due to space limitations. The readers are referred to Kuo 1996 and Huang \& Ochi 2004 for the relevant discussion. 
argument, as is well known in the literature (see Huang 1982 and Tsai 1994, among others).

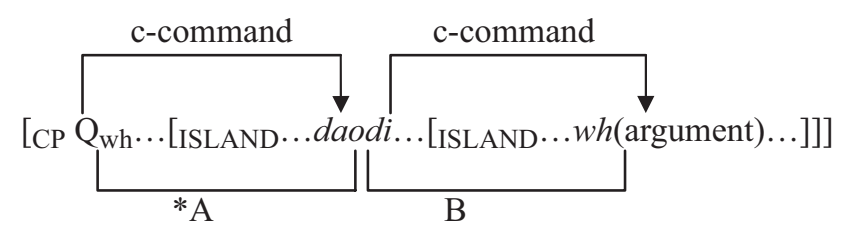

In the spirit of Cinque's (1999) phrase structure analyses, Huang \& Ochi also propose that daodi occupies the specifier of an (interrogative) Attitude Phrase in (7) in the left periphery of IP. ${ }^{5,6}$

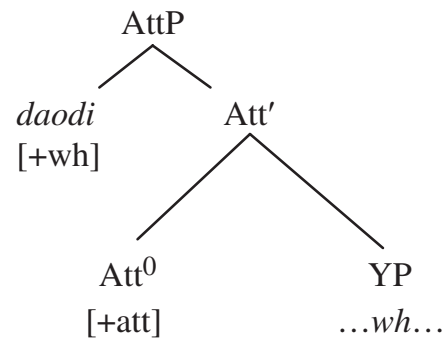

The existence of this Attitude Phrase signals that you have "a question with an attitude" and the head of the Attitude Phrase encodes the logophoric feature of this attitude (Huang \& Ochi 2004:7), which must be ascribed to either the external speaker of the entire utterance or the internal speaker (typically the subject referent of certain speech-act verbs). This proposal is highly related to my analysis in this paper because the Attitude Phrase encodes the logophoric feature of daodi's attitude, whose ascription, as I will argue, should be represented within the syntactic computation.

It is worth pointing out that although Huang \& Ochi (2004) note the logophoricity of the negative attitude carried by daodi 'the-hell', they did not further develop the idea regarding its potential influence on syntactic computation, which I argue to be the key component of this analysis explaining the new empirical observations presented in the next section.

\footnotetext{
${ }^{5}$ Huang \& Ochi (2004:7, fn.6) suggest that the Attitude Phrase is very similar to the Source/Self/Pivot Phrase or the Point-of-View Phrase proposed by Huang \& Liu (2001) that hosts the LF-moved logophor ziji in MC.

${ }^{6}$ Speas (2004), Tenny \& Speas (2003), and Tenny (2006) propose similar ideas that pragmatic notions such as sentience, point of view, and evidentiality should be syntactically encoded to explain constraints on the grammaticalization of possible pragmatic roles and a peculiar person-feature constraint of the subject of certain predicates in Japanese. The analysis in this paper is in part inspired by their research on the syntaxdiscourse interface. Additionally, Pires \& Taylor (2007) argue for encoding in the syntax a complementizer that maps to "common ground," and which yields wh-in-situ in English and Portuguese. Due to space limitations, I refer readers to these interesting works for comparison.
} 


\section{Chao-Ting Tim Chou}

The remainder of this paper is organized as follows. Section 2 presents two previously unnoted observations regarding the MC wh-the-hell questions. In section 3, I briefly review previous analyses of how come and argue that they do not explain the phenomena this paper aims to account for. Section 4 is the analysis of the data presented in section 2 and the discussion of how this analysis can also naturally and formally capture certain properties of the MC logophor ziji. Section 5 is a brief comparison with den Dikken \& Giannakidou's (2002) work on wh-the-hell in English. Finally I summarize the paper in section 6.

\section{The New Data}

\subsection{Incompatibility with Causal Zenme}

Although daodi 'the-hell' typically combines with a wh-associate to form an attitudebearing wh-the-hell question in $\mathrm{MC}$, it is not allowed to co-occur with causal zenme 'how come' to construct an attitude-bearing question, the expression of which constitutes an inquiry about cause or reason:

(8) (*Daodi) ta zenme zuotien mei lai shang ke?

THE-HELL he how-come yesterday not come attend class

'How come (*the hell) he did not come to class yesterday?'

This incompatibility is surprising because daodi can combine with weishenme 'why', which is also an adverb expressing an inquiry about the reason for or cause of the propositional content of the question:

(9) Daodi ta weishenme zuotien mei lai shang ke?

THE-HELL he why yesterday not come attend class

'Why the hell didn't he come to class yesterday?'

To the best of my knowledge, this incompatibility has not been previously noted or accounted for. In section 3, I will show that the previous studies of how come cannot provide an adequate explanation for this incompatibility in MC.

\subsection{The Matrix Subject Person-Feature Constraint}

As already shown in (5) (repeated here as (10)), daodi can take matrix scope while staying in the embedded clause:

(10) $\mathrm{Ni}$ renwei [Lisi daodi xihuan shei]?

you think Lisi THE-HELL like who

'Who the hell do you think Lisi likes?' 
Nevertheless, this distribution is, in fact, highly restricted by the person feature of the matrix subject. We cannot replace the second-person matrix subject in (10) with a third-person one as in (11). ${ }^{7,8}$

\section{(11) *Zhangsan renwei [Lisi daodi xihuan shei]? \\ Zhangsan think Lisi THE-HELL like who \\ 'Who the hell does Zhangsan think Lisi likes?'}

Interestingly, if we put daodi in the matrix clause, the person-feature constraint is lifted with the same intended interpretation. Compare (10) and (11) with (12a,b).

${ }^{7}$ The person feature of the matrix subject in (10) cannot be first person as in (i). This is because it is pragmatically odd, and thus must be distinguished from the syntactically ill-formed (11).

(i) \#Wo renwei Lisi daodi xihuan shei?

I think Lisi THE-HELL like who

'Who the hell do I think Lisi likes?'

The pragmatic oddity of (i) could be remedied as in (ii) in a context in which I lose my memory due to brain injury.

(ii) $\mathrm{Ni}$ keyi gaosu wo [wo renwei [Lisi daodi xihuan shei]] ma? you can tell me I think Lisi THE-HELL like who Qyes-no 'Can you tell me who the hell I thought Lisi likes?'

By contrast, no context can render (11) acceptable.

${ }^{8}$ One may wonder if the embedded clause in (10) is actually a direct question with ni renwei 'you think' simply as a parenthetical interjection meaning "in your opinion" as in (i), so that daodi is actually in the root clause of a direct question.

(i) $\mathrm{Ni}$ renwei, Lisi daodi xihuan shei? you think Lisi THE-HELL like who

'In your opinion, who the hell does Lisi like?'

The evidence against this line of analysis comes from the distribution of causal zenme 'how come'. As noted by Collins (1991), the construal of how come in (ii) is not ambiguous; that is, how come cannot originate from the embedded clause.

(ii) How come Bill thought Mary quit?

a. What is the cause of Bill's thinking that Mary quit?

b. *What is the cause of Mary's quitting that Bill thought?

Similarly, in MC, causal zenme cannot occur in the embedded clause, as in (iiia), unless the embedded clause is an interrogative $\mathrm{CP}$ as in (iiib).

(iii) a. *Zhangsan renwei [Lisi zenme cizhi le]. Zhangsan think Lisi how-come quit ASP

b. Zhangsan xiang-zhidao [Lisi zenme cizhi le]. Zhangsan wonder Lisi how-come quit ASP 'Zhangsan wonders how come Lisi quit.'

If the embedded clause of (10) is actually a direct question with ni renwei 'you think' as a parenthetical interjection, causal zenme should be able to occur in it; however, this is not borne out as evidenced by (iv). We take this as evidence against the direct question analysis of (10).

(iv) $* \mathrm{Ni}$ renwei Lisi zenme cizhi le ne? you think Lisi how-come quit ASP $\mathrm{Q}_{w h}$ 
(12) a. Ni daodi renwei [Lisi xihuan shei]? you the-hell think Lisi like who 'Who the hell do you think Lisi likes?'

b. Zhangsan daodi renwei [Lisi xihuan shei]? Zhangsan the-hell thinks Lisi like who 'Who the hell does Zhangsan think Lisi likes?'

Also, the person feature of the embedded subject does not affect the grammaticality of either (10) or (11), as shown by (13).
a. $\mathrm{Ni}$ renwei [ni/wo daodi xihuan shei]? you think you/I THE-HELL like who
'Who the hell do you think you/I like?'
b. *Zhangsan renwei [ni/wo daodi xihuan shei]? Zhangsan think you/I THE-HELL like who 'Who the hell does Zhangsan think you/I like?'

This aspect of the distribution of daodi can be summarized in diagram (14). Daodi cannot occur in the embedded clause of a direct question when the matrix subject is a third-person NP:

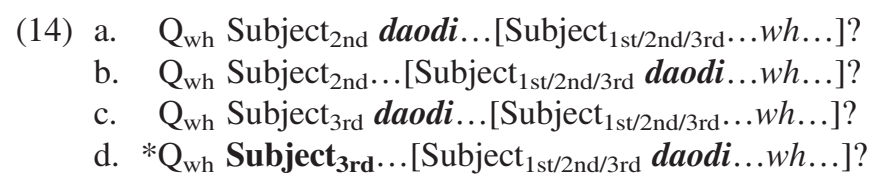

It is clear that the embedded occurrence of daodi in direct questions is not constrained by the person feature of the embedded subject. It is the person feature of the matrix subject that constrains the distribution of embedded daodi.

\section{Previous Studies of How Come}

Developing a suggestion in Collins 1991 concerning how come, Fitzpatrick (2005) advances a factivity analysis of how come questions to explain an array of distinctions between why and how come such as the contrast with respect to rhetorical questions in $(15)$.

(15) a. Why would John leave?

b. *How come John would leave?

The key idea in Fitzpatrick's analysis of the various disparities between how come and why is that only how come carries a genuine existential presupposition of the truth of the propositional content of the question. Also, rhetorical questions are negatively biased questions to which the speaker assumes that only a negative answer is the 
correct answer. Therefore, (15b) is ruled out due to the clash between the existential presupposition carried by how come in (16a) and the negative bias of the rhetorical question in (16b) (henceforth, the factivity-bias clash). ${ }^{9}$

(16) a. Presupposed: He would leave.

b. Negative bias: He would not leave.

On the basis of the contrast in (15), Fitzpatrick claims that in contrast to how come, why does not carry the existential presupposition of the truth of the propositional content of the question, and hence does not conflict with the negative bias of a rhetorical question. The apparent existential presupposition of a why question actually comes from the inference from the set of its possible answers as in (17) (Fitzpatrick 2005:7). The inference from all the possible answers to a why question like (17) is that John hit Bill (for whatever reason[s]), and this leads to the apparent factivity presupposition of a why question.

\section{(17) Why did John hit Bill?}

\{John hit Bill for reason x, John hit Bill for reason y, John hit Bill for no reason

First, we agree that how come presupposes the truth of the propositional content of the question it occurs in, but I do not think the factivity-bias clash can help explain the illicit combination of causal zenme with daodi to form a wh-the-hell question, which according to den Dikken \& Giannakidou (2002:43-44), carries a negative attitude toward the propositional content of the wh-question (i.e., the state of affairs described in the propositional content of a wh-the-hell question is characterized by the speaker as an event that s/he assumed should not happen). One possible way for Fitzpatrick's (2005) analysis to capture this incompatibility might be to say that the presupposition of how come conflicts with the negative attitude of a wh-the-hell question as well. However, there are good reasons against this extension. Conceptually, it is perfectly reasonable and common for one to wish or think that a certain true proposition should not happen. Empirically, consider (18) with the factive verb regret.

(18) John regrets that he stole the book yesterday.

Factive verbs like regret presuppose the truth of the proposition of their complement clause. However, the verb regret also carries a negative attitude on the part of the

\footnotetext{
${ }^{9}$ An anonymous reviewer suggests that the presupposition of 'how come John left' is 'John left for some reason' rather than just 'John left', as assumed in Fitzpatrick's paper, and 'how come John would leave?' would be a felicitous rhetorical question only if the speaker has the expectation that 'there is no reason for John to leave.' This speaker's expectation conflicts with the presupposition of how come, and the infelicity of this rhetorical question is correctly predicted even if the speaker does not have a negative attitude toward the actual leaving. We agree that the infelicity of (15b) may be derived without assuming the negative attitude carried by how come argued for in this paper, but the goal of this section is to show that a factivity analysis of how come is not enough to explain the incompatibility between causal zenme 'how come' and daodi 'the hell' in MC, which is the main issue in this paper.
} 
referent of its subject that s/he would prefer that the event expressed by the embedded proposition were not to have happened. If factivity conflicts with negative attitude, (18) would be ungrammatical, but this is not borne out. Thus, we cannot exclude the combination of daodi and causal zenme by a constraint banning the combination of factivity and negative attitude.

Second, as an anonymous reviewer correctly points out, most semantic analyses of questions would have both 'why did Mary leave' and 'how come Mary left' presupposing the truth that Mary left. Even though Fitzpatrick (2005) contends that only how come carries the true existential presupposition of truth of the propositional content of the question, while the apparent presuppositionality of why questions should be viewed as the inference from the set of its possible answers, ${ }^{10}$ it is not clear how this distinction can help us analyze the contrast between causal zenme and reason weishenme with respect to the combination with daodi. The truth of the propositional content of a weishenme 'why' question is clearly presupposed by the speaker as well, regardless of the source of this presupposition.

Therefore, I conclude that the factivity analysis does not provide an explanation for the incompatibility between daodi 'the hell' and causal zenme 'how come'. In the next section, I present a formal analysis that capitalizes on the logophoric negative attitudes of daodi and causal zenme to account for the new observations. Moreover, it will be shown that this proposal provides further refinements of Huang \& Liu's (2001) pragmatic account of the Blocking Effects of the logophor ziji in MC.

\section{The Analysis}

I propose that the solution to the new data presented in section 2 is related to the logophoric negative attitudes carried by daodi 'the hell' and causal zenme 'how come' toward the propositional content of the question they occur in. Semantically, the negative attitude of these elements is logophoric in the sense that it must be ascribed to either the external speaker or the internal speaker (typically the subject of certain speech-act verbs like think) for full interpretation of these attitude-bearing questions (see Sells 1987, Chierchia 1989, and Huang \& Liu 2001 for logophoricity ascription).

\subsection{The Logophoric Negative Attitudes of Daodi and Causal Zenme}

As pointed out explicitly by den Dikken \& Giannakidou (2002:43-44), “wh-the-hell in English carries a presupposition of negative attitude on the part of the speaker." Specifically, the speaker of a wh-the-hell question holds a negative attitude toward the proposition expressed in the interrogative. For instance, the speaker of (19) thinks that for any $\mathrm{x}$, such that $\mathrm{x}$ bought this book, $\mathrm{x}$ should not have done this.

\footnotetext{
${ }^{10}$ Fitzpatrick seems to suggest that the presupposition of how come is based on its inherent semantics, whereas that of why questions is inferred from its set of possible answers as a pragmatic consequence. Despite this alleged underlying difference, the speaker of why questions clearly presupposes the truth of the propositional content in the question (cf. \#I don't believe that John left, but I want to know why John left.), and it is not clear why this presupposition does not conflict with the negative bias of a rhetorical question.
} 
(19) Who the hell bought this book?

As for the MC counterpart daodi, Huang et al. (2009:237, fn. 2) point out that daodi in MC wh-the-hell questions, conveys " an urgent desire, even a sense of impatience, on the part of the speaker to get to the specific information being requested."

I would like to provide two additional comments regarding the presupposition of the speaker's attitude of wh-the-hell in MC. First of all, Den Dikken and Giannakidou's (2002) observation on the negative attitude of the speaker in a wh-the-hell question deserves elaboration. In particular, the ascription of this negative attitude calls for a formal mechanism. Consider (20) and (21) regarding the negative attitude ascription of daodi.
Lisi daodi mai le shenme?
Lisi THE-HELL buy ASP what
'What the hell did Lisi buy?'

\section{(21) Zhangsan xiang-zhidao [Lisi daodi mai le shenme]. Zhangsan wonder Lisi THE-HELL buy ASP what 'Zhangsan wonders what the hell Lisi bought.'}

In the direct question (20), the negative attitude of daodi is ascribed to the external speaker of the question, whereas it is the matrix subject referent, the "internal speaker' Zhangsan, that is holding this negative attitude in the indirect question (21). ${ }^{11}$ Note that the attitude holder of daodi can only be determined when the syntactic derivation unfolds, given that it depends on the position of daodi in a sentence. Accordingly, we should have a derivational mechanism responsible for this value-setting.

Second, causal zenme 'how come' carries another kind of speaker's negative attitude toward the propositional content of the question. According to Tsai (2004:5), causal zenme contributes a sense of speaker's counter-expectation. More specifically, the state of affairs expressed in the propositional content of a causal zenme question does not match the speaker's expectation regarding what should be the real-world situation. As we will see, it is precisely this speaker's negative attitude that distinguishes causal zenme 'how come' and reason weishenme 'why' with respect to their different compatibility with daodi. To see the mismatch between the

\footnotetext{
${ }^{11}$ Note that (21) cannot mean that both the external speaker and the matrix subject referent Zhangsan, as the internal speaker of the embedded clause, hold the negative attitude. Also consider the direct questions (i) and (ii).

(i) Who the hell did John say Bill saw?

(ii) $\mathrm{Ni}$ renwei Lisi daodi xihuan shenme? you think Lisi THE-HELL like what 'What the hell do you think Lisi likes?'

In direction questions like (i) and (ii), only the external speaker, rather than the matrix subject referent (John and $n i$ 'you'), holds the negative attitude.
} 
propositional content of the causal zenme question and the speaker's expectation, consider (22).

(22) Zhangsan zenme zai ku?

Zhangsan how-come ASP cry

'How come Zhangsan is crying?'

The speaker of (22) holds the negative attitude that Zhangsan's crying is contrary to his/her expectation, and hence is asking about the cause of this unexpected state of affairs. ${ }^{12}$

Further examples of speaker's use of causal zenme to express his/her counterexpectation regarding the real world are the following interrogatives that inquire about the reason for or the cause of a mathematical fact (one plus one equals two):

(23) a. Yi jia yi weishenme hui denyu er? one plus one why would equal two 'Why does one plus one equal two?'

b. \#Yi jia yi zenme hui denyu er? one plus one how-come would equal two '\#How come one plus one equals two?'

The sentences in (23a) and (23b) differ minimally in the interrogative adverb they use. However, (23b) is semantically and pragmatically odd. The subtle yet crucial distinction between them lies in the speaker's counter-expectation toward the propositional content of the question. By uttering (23b), the speaker is not only asking about the cause of the truth of the mathematical equation, but is also expressing his/ her negative attitude toward it; that is, the speaker thinks that the mathematical equation does not match the real-world fact, and asks for the cause of this mistaken equation. With this much said, it is obvious that the oddity of (23b) stems from the clash between this speaker's negative attitude induced by causal zenme and the realworld mathematical fact; that is, one plus one indeed equals two. As a result, an interrogative like (23b) is not a felicitous information-seeking question. Note that compared to causal zenme, reason weishenme 'why' is rather neutral with respect to the speaker's attitude toward the propositional content of the question. The speaker of (23a) simply inquires about the principles underlying the mathematical equation, which s/he regards as the truth. The oddity of (23b), when compared with (23a),

${ }^{12}$ Consider the contrast between how come and why in this aspect:

(i) I expected Zhangsan to be crying, but

a. why is he crying?

b. *how come he is crying?

Example (ib) is bad precisely because the speaker cannot utter a how come question that asks for the cause of some event or state that is consistent with his/her expectation. 
shows the contrast between causal zenme and reason weishenme in the negative attitude carried by the former. ${ }^{13}$

The prediction is that we can use causal zenme to question a proposition that is definitely false because the speaker can felicitously express his/her negative attitude that the propositional content does not match the real-world fact. This prediction is borne out. Consider the contrast between (23b) and (24). ${ }^{14}$

(24) Yi jia yi zenme hui denyu san?

one plus one how-come would equal three

'How come one plus one equals three?'

Given that the propositional content "one plus one equals three", is not a true mathematical fact, it is licit for the speaker to express his/her negative attitude that this equation does not match the real-world fact, and inquire about the cause of this false equation.

Additionally, the logophoric property of daodi's negative attitude carries over to the negative attitude of causal zenme as well. Compare the attitude ascription of (25) and (26).

\section{Lisi zenme mei lai shang ke?}

Lisi how-come not come attend class

'How come Lisi did not attend the class?'
Zhangsan xiang-zhidao [Lisi zenme mei lai shang ke].
Zhangsan wonder Lisi how-come not come attend class
'Zhangsan wonders how come Lisi did not attend the class.'

Just like the daodi question counterparts in (20) and (21), the ascription of the negative attitude of causal zenme varies according to its overt syntactic position. In direct questions such as (20) and (25), it is the external speaker holding the negative attitude, whereas in indirect questions such as (21) and (26), the negative attitude goes only to the matrix subject referent (i.e., the internal speaker of the embedded clause).

Summing up thus far, the negative attitudes carried by daodi 'the-hell' and causal zenme 'how come' must be ascribed to either the external speaker of the entire utterance or the internal speaker (typically the subject of certain speech-act verbs) for full interpretation of an attitude-bearing question. Any adequate analysis of questions containing daodi and causal zenme in MC must take this logophoric property into

\footnotetext{
13 The oddity of (23b) also indicates that Fitzpatrick's (2005) factivity analysis of how come in English is not sufficient for causal zenme in MC. Causal zenme, carrying the factivity presupposition, should be able to combine with a true proposition expressing a mathematical fact to form an interrogative, but this is not borne out. Therefore, causal zenme 'how come' must have something more than this presupposition that is responsible for the oddity of (23b). As argued in the text, it is the speaker's negative attitude that leads to this anomaly.

${ }^{14}$ One context in which (24) is a felicitous question is when a young child, who is just beginning to learn basic arithmetic, thinks that one plus one equals three, and one may correct him/her by asking (24). On the other hand, one can never utter (23b) to correct the child.
} 
consideration. In the next subsection, it will be shown how this pragmatic concept may be formalized and integrated into the syntactic computation.

\subsection{The Point-of-View Feature and the Point-of-View Operator}

To formalize the logophoric property of the negative attitudes carried by daodi and causal zenme, I propose that there is an unvalued Point-of-View feature (POV feature) in both doadi and causal zenme, and the POV feature needs to be valued via the probe-goal relationship with the closest c-commanding Point-of-View operator (POV-op) in the left periphery of $\mathrm{CP}^{15}$ to identify "the logophoric orientation" (to quote a comment from a reviewer) for full interpretation of the attitude-bearer of these attitude-bearing questions.

The POV-op consists of two POV features: [discourse participant] and [addresser] (henceforth, [d] and [a], respectively), as shown in (27). ${ }^{16}$

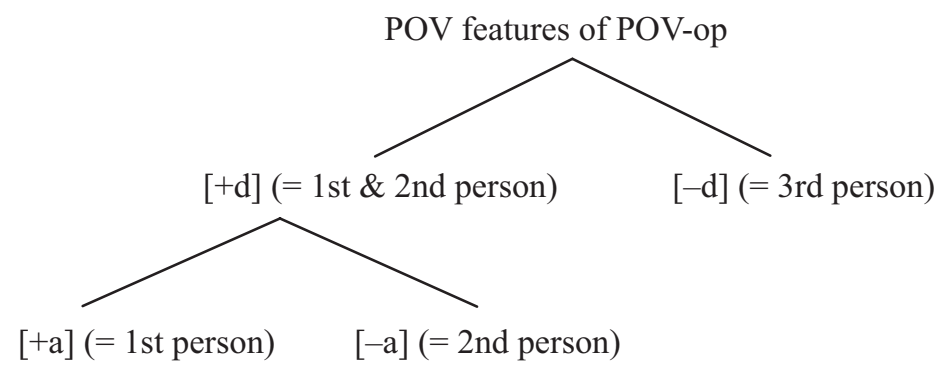

The node $[+\mathrm{d}]$ encompasses first and second person, which are the addresser and the addressee in the discourse, and the node $[-\mathrm{d}]$ represents third person. Further, the feature [a] distinguishes first person from second person.

Note that there is a critical distinction between the matrix-clause POV-op and the POV-op in the embedded clause. The POV features of the matrix POV-op is always $[+\mathrm{d},+\mathrm{a}]$, which represents the point of view of the external speaker of the entire utterance, whereas those of the embedded POV-op are indeterminate with respect to "logophoric orientation," which is determined by the person feature of the minimal c-commanding subject as shown in the diagrams in $(28) .{ }^{17,18}$

\footnotetext{
${ }^{15}$ The POV-op may be hosted by a phrase encoding pragmatic information such as the Evaluative Mood Phrase in Cinque's (1999) theory of phrase structures.

${ }^{16}$ Harley \& Ritter (2002) propose a morphological feature geometry for pronouns to capture the crosslinguistic uniformity and variations of the acquisition order and the inventory of pronouns in a wide range of languages. The POV features of POV-op in (27) is inspired by and adapted from a portion of their geometry. However, (27) is different from their geometry not only in form but also in its theoretical purpose. I adopt a binary-valued feature system (they intend a unary-valued geometry), and the features in (27) are meant to denote only the logophoric orientation of point of view.

${ }^{17}$ Note that $[-\mathrm{d},+\mathrm{a}]$ is not a possible combination; an addresser must be a discourse participant by definition.

${ }^{18}$ As an anonymous reviewer points out, if the external speaker is viewed as the subject of a performative verb in some representation, the POV setting of the matrix POV-op can be assimilated to the one of the embedded POV-op. Both are determined by the minimal c-commanding subject.
} 
(28) a. [Matrix POV-op $\left.{ }_{[+\mathrm{d},+\mathrm{a}]} \ldots \operatorname{Subj}_{1} \ldots\left[\mathrm{POV}-\mathrm{Op}_{[+\mathrm{d},+\mathrm{a}]} \ldots\right]\right]$

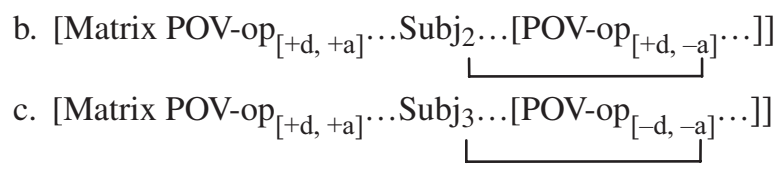

Next, we turn to the POV feature of daodi and causal zenme. Each of them contains the single unvalued $[u \mathrm{~d}]$ feature, which has to be valued via probe-goal relation with the POV-op. Additionally, daodi and causal zenme have to adjoin covertly to POV-op to obtain their scope over the attitude-bearing question. Let us see how the valuation proceeds case by case. Consider (29), a direct question.

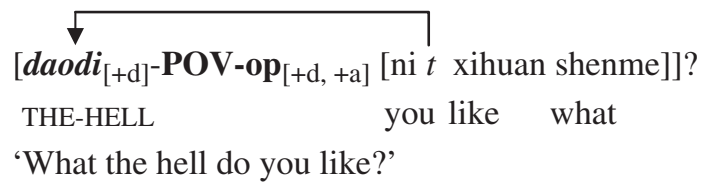

First, the [ud] of daodi is valued as [+d] via probe-goal relation with the matrix POVop. This identifies the logophoric orientation of daodi as the one belonging to the discourse participants. Second, daodi adjoins to POV-op to obtain scope over the attitude-bearing question. Last but not least, the amalgam of POV features of daodi and the matrix POV-op, $[+\mathrm{d},+\mathrm{a}]$, correctly identifies the attitude-bearer of daodi as the addresser of the discourse participants, and thereby we have a full interpretation of this attitude-bearing question.

Next, consider the derivations related to the POV valuation in the indirect question (30).

(30) Zhangsan xiang-zhidao [Lisi daodi xihuan shenme].

Zhangsan wonder Lisi THE-HELL like what

'Zhangsan wonders what the hell Lisi likes.'

a. [daodi $[u \mathrm{~d}]^{-\mathrm{POV}-\mathrm{op}}[\boldsymbol{u \mathrm { d } , \boldsymbol { u a } ]} \mathrm{LS} t$ xihuan shenme $]$

b. ZS xiang-zhidao $\left[\operatorname{daodi}_{[-\mathbf{d}]}-\mathrm{POV}-\mathrm{op}_{[-\mathbf{d},-\mathbf{- a}]}\right.$ LS $\left.t \ldots\right]$

In (30a), daodi adjoins to the embedded POV-op, taking scope over the embedded question. Also, note that neither daodi nor the embedded POV-op has valued POV features at this stage of derivation because both are indeterminate with respect to their logophoric orientation, which is determined by the minimal c-commanding subject, 
as shown in (30b). ${ }^{19}$ Also, the POV features amalgam $[-\mathrm{d},-\mathrm{a}]$ of daodi and the embedded POV-op in (30b) correctly identifies the bearer of the negative attitude of daodi as the non-discourse-participant matrix subject referent Zhangsan.

With the mechanism of POV valuation, we are now ready to explain the personfeature constraint of the matrix subject in MC wh-the-hell questions. When daodi occurs in the embedded clause in a direct question, the attitude-bearer of daodi is always the external speaker of the entire question. When the matrix subject of a direct question is a second-person NP, the relevant derivations of this interpretation would be as in (31).
(31) Ni renwei [Lisi daodi xihuan shenme]?
you think Lisi THE-HELL like what
'What the hell do you think Lisi likes?'

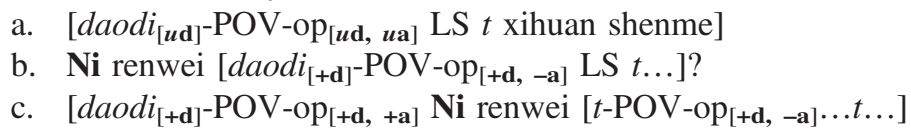

The diagrams in $(31 \mathrm{a}, \mathrm{b})$ are similar to $(30 \mathrm{a}, \mathrm{b})$ except for the person feature of the matrix subject and the selection of the main verb. The POV features of daodi and the embedded POV-op are determined by the person feature of the minimal c-commanding subject, as shown in (30b) and (31b). Besides, given that (31) is a direct question, daodi has to adjoin successive-cyclically to the matrix POV-op to obtain matrix scope over the entire question. Crucially, the POV feature of daodi is consistent with the POV features of the matrix POV-op at its scope position, so we obtain the correct ascription of daodi's negative attitude to the external speaker of the direct question in (31) with the POV features amalgam $[+\mathrm{d},+\mathrm{a}]$ of daodi and the matrix POV-op.

Next, consider the direct question (32) with a third-person matrix subject, the case illustrating the matrix-subject person-feature constraint. Note that like (31), (32) is a direct question in which the negative attitude carried by daodi should be ascribed only to the external speaker of the entire question.

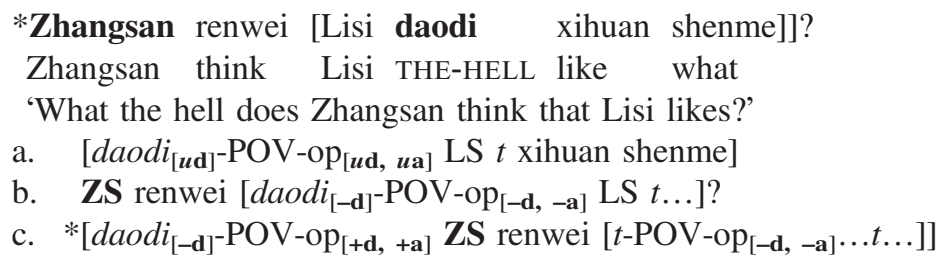

${ }^{19}$ The derivational relation between the embedded POV-op/daodi and the minimal c-commanding subject in (30b) is similar to the one between the null operator and the local subject in the derivation of a tough-construction in (i) (see Chomsky 1982, 1986).

(i) Fred said John is easy [Op PRO to please $t]$.

The null operator within the embedded clause in (i) is anaphoric in the sense that its referent is indeterminate until John is merged in the derivation. Also, the relation is local because the antecedent can only be the closest subject John, rather than the remote Fred. 
Examples (31) and (32) differ only in the person feature of the matrix subject. This affects the logophoric orientation the embedded POV-op and daodi as seen in (31b) and (32b). The reason why (32) is ungrammatical stems from the clash of the POV features of daodi and the matrix POV-op in (32c). The derivations in (32) yield an ill-formed CI representation that cannot identify the bearer of daodi's negative attitude.

Our analysis predicts that if we put daodi in the matrix clause rather than in the embedded clause, the sentence should be good because the POV feature of daodi would be directly valued by $[+\mathrm{d},+\mathrm{a}]$ of the matrix POV-op, generating the correct interpretation. This prediction is borne out (as was shown earlier in (12b)).

(33) daodi $_{[+\mathbf{d}]}-\mathbf{P O V}-\mathbf{o p}_{[+\mathbf{d},+\mathbf{a}]}$ Zhangsan $t$ renwei [Lisi xihuan shei]? THE-HELL Zhangsan think Lisi like who

'Who the hell does Zhangsan think Lisi likes?

The same mechanism also applies to zenme questions, as in (34)-(36). ${ }^{20}$

(34) POV-op P+d,+a] $]\left[\right.$ ni zenme $_{[+\mathbf{d}]}$ mei lai $]$ ? you how-come not come

'How come you did not come?'

(35) Ni xiang-zhidao $\left[\mathbf{P O V}-\mathbf{o p}_{[+\mathbf{d},-\mathbf{a}]}\right.$ Lisi $\mathbf{z e n m e}_{[+\mathbf{d}]}$ mei lai] ma?

you wonder Lisi how-come not come Qyes-no

'Do you wonder how come Lisi did not come?'

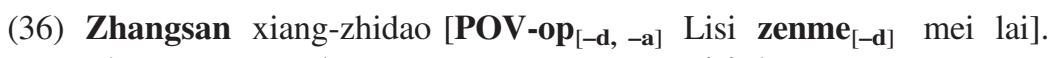

Zhangsan wonder Lisi how-come not come

'Zhangsan wonders how come Lisi did not come.'

The generalization emerging from the discussion so far is (37).

(37) Generalization of POV valuation of daodi/causal zenme

The POV feature of daodi/causal zenme must match the POV features of the POV-op at their scope position to ensure correct ascription of their negative attitudes.

Now, if we combine daodi and zenme in one question, the relevant structure would be (38). The incompatibility between daodi and causal zenme is ruled out by minimality of POV probe-goal relation. Only the POV feature of daodi could be

20 The covert movement of zenme is omitted here for expository convenience. 
valued by POV-op, which leaves the POV feature of causal zenme unvalued, causing the derivational crash. Therefore, there is no well-formed CI representation of this word string. ${ }^{21}$

$$
\begin{gathered}
* \text { POV-op } \\
{[+\mathbf{d},+\mathbf{a}]} \\
\text { Lisi THE-HELL how-come not come } \\
\text { Lisiodi } \\
\text { Intended: 'How come the hell Lisi did not show up?' }
\end{gathered}
$$

This line of analysis gives the following correct prediction: if we split zenme thow come' and daodi 'the-hell' in two interrogatives, the construction should be well formed because each of them is valued by a separate POV-op, not intervening with each other's valuation. The sentences in (39) substantiate this prediction.

\section{(39) a. Daodi Zhangsan weishenme xiang-zhidao [Lisi zenme mei lai]? THE-HELL Zhangsan why wonder Lisi how-come not come 'Why the hell does Zhangsan wonder how come Lisi did not come?' \\ b. Lisi zenme hui xiang-zhidao [Zhangsan daodi xihuan shei]? Lisi how-come would wonder Zhangsan THE-HELL like who 'How come Lisi would wonder who the hell Zhangsan likes?'}

The POV valuation analysis proposed here constitutes an explicit mechanism for the ascription of the negative attitudes of daodi and causal zenme. They are "doubly anaphoric" (to quote from Huang \& Tang's [1991:274-275] comments on the bare reflexive ziji in MC) in the sense that they are indeterminate in both their logophoric orientation and their identification of the attitude-bearer. The logophoric orientation is determined either by the matrix POV-op as in (29) and (34) or by the minimal c-commanding subject as in (30)-(32) and (35)-(36), whereas the attitude-bearer is identified by the amalgam of the POV features of daodi/causal zenme and the POVop at their scope position. Crucially, the value of the former cannot clash with the latter, which is in essence captured by generalization (37). Moreover, this helps us deal with two otherwise unexplained observations about the wh-the-hell questions in MC. That is, daodi cannot occur in the embedded clause of a direct question when the matrix subject is a third-person NP, and daodi is not compatible with causal zenme. In the next subsection, this analysis is extended to another element that has also been analyzed as sensitive to point of view-the logophor ziji in MC.

\footnotetext{
${ }^{21}$ An anonymous reviewer suggests another possible line of reasoning based on the ECP to rule out this illicit combination. Given that both daodi and zenme are adjuncts subject to movement to the POV-op, the configuration would be ruled out on a par with the following sentences:

(i) *Why did you fix the car how?

(ii) *How did he leave early why?

The traditional ECP account of (i) and (ii) (Lasnik \& Saito 1984, 1992) is that both of the adjuncts need to be antecedent-governed, but only one of them satisfies this requirement. I leave the issue open here as to which line of analysis is preferable.
} 


\subsection{Extension: The POV Valuation of the Mandarin Logophor Ziji}

The reflexive ziji in MC can function either as a locally bound anaphor just like himself or herself in English or as a long-distance bound logophor, as shown by (40).

(40) Zhangsan ${ }_{i}$ renwei [Lisi ${ }_{j}$ kan-bu-qi ziji $\left._{i j}\right]$.

Zhangsan think Lisi look-not-up self

'Zhangsan ${ }_{\mathrm{i}}$ thinks Lisi $\mathrm{j}_{\mathrm{j}}$ looks down on him $\mathrm{i}_{\mathrm{i}}$ himself $_{\mathrm{j}}$.'

There is a well-known property of the logophoric use of ziji-the Blocking Effects, first noted by Y.-H. Huang (1984). The long-distance construal of ziji may be blocked under various conditions (for a detailed review, see Huang \& Liu 2001). Here we focus only on the blocking induced by a first-/second-person local antecedent. Compare (40) with (41), where the third-person embedded subject Lisi is replaced by a first-/second-person NP, with the result that ziji cannot refer to the remote antecedent. ${ }^{22}$
a. Zhangsan ${ }_{\mathrm{i}}$ renwei [wo $\mathbf{w o}_{\mathbf{j}}$ kan-bu-qi $\left.\mathbf{z i j i}_{\mathbf{j}} / *_{\mathrm{i}}\right]$.
Zhangsan think I look-not-up self
'Zhangsan thinks I $_{\mathrm{j}}$ look down on ${ }^{*} \mathrm{him}_{\mathrm{i}} /$ myself $_{\mathrm{j}}$.'
b. Zhangsan ${ }_{i}$ renwei $\left[\mathbf{n i}_{\mathbf{j}}\right.$ kan-bu-qi $\mathbf{z i j i}_{\mathbf{j}}$; $\left._{\mathbf{i}}\right]$.
Zhangsan think you look-not-up self

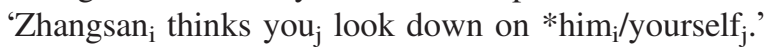

Developing the functional approach in Huang et al. 1984, Huang \& Liu (2001) explain the Blocking Effects in terms of a pragmatic strategy of avoiding perspective conflicts. Specifically, the logophor ziji is equivalent to wo ' $\mathrm{T} / \mathrm{me} / \mathrm{my}$ ' anchored to the matrix subject Zhangsan that denotes the internal speaker of the embedded clause in the direct discourse representation as in (42), and the first-I second-person pronoun wo/ni in the embedded clause of (41) is anchored to the external speaker of the entire utterance. This produces a perspective conflict in the

\footnotetext{
${ }^{22} \mathrm{Xu}(1993)$ notes that there exists a person asymmetry between first-/second-person and third-person NPs with respect to the Blocking Effects. Compare (41) with the following examples where the local antecedent of $z i j i$ is a third-person NP and the remote antecedent is a first-/second-person NP.

(i) $\mathrm{Wo}_{\mathrm{i}}$ danxin [Zhangsan ${ }_{\mathrm{j}}$ hui piping $\left.\mathrm{ziji}_{\mathrm{j} / \text { ? }} \mathrm{i}\right]$.

I worry Zhangsan will criticize self

'I am worried that Zhangsan will criticize himself/??me.'

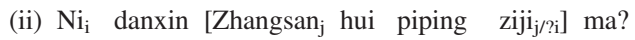

you worry Zhangsan will criticize self $\mathrm{Q}_{\text {yes-no }}$

'Are you worried that Zhangsan will criticize himself/?you?'

As noted by Huang \& Liu (2001:49, fn. 2), although the local construal of ziji in (i) and (ii) is the preferred reading over the long-distance construal, it is obvious that the long-distance construal is impossible in (41) with the first-/second-person NP local antecedent. My intuition for this contrast is that the long-distance construal in (i) is even more difficult, if not impossible, to get than it is in (ii). Here I focus only on the clear blocking induced by a local first-/second-person antecedent in (41) and leave this contrast in the degree of acceptability for future research.
} 
direct discourse representation in (42b) because the logophor would need to be anchored to the internal speaker for long-distance construal, whereas the embedded subject is anchored to the external speaker, a situation that Huang \& Liu claim is difficult to sort out perceptually:

(42) a. Zhangsan renwei, "Lisi kan-bu-qi wo."

Zhangsan thinks, "Lisi looks down on me."

b. \#Zhangsan renwei, "wo/ni kan-bu-qi wo."

Zhangsan thinks, "I/you look down on me."

This pragmatic explanation admirably explains most of the data concerning the Blocking Effects. Therefore, I do not attempt to claim that the POV valuation mechanism, as it is formulated in the current paper, could outperform this pragmatic account with respect to the empirical coverage of the data. However, I would like to point out that the core pragmatic principle of avoiding perspective conflicts underlying Huang and Liu's account wrongly predicts the grammatical long-distance construal of ziji in (43a), with the direct discourse representation (43b). On their view, the underlying wo ' $\mathrm{I}$ ' of ziji in (43b) is anchored to the first-person matrix subject, which denotes the external speaker of the entire utterance. This anchoring should not have any perspective conflict with the second-person embedded subject $n i$ 'you', which is also anchored to the external speaker.

(43) a. $\mathrm{Wo}_{\mathrm{i}}$ renwei $\left[\mathrm{ni}_{\mathrm{j}}\right.$ bu yinggai kan-bu-qi $\left.\mathbf{z i j i}_{\mathrm{j} / *_{\mathrm{i}}}\right]$.

I think you not should look-not-up self

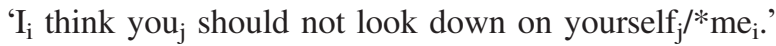

b. Wo renwei, "ni bu yinggai kan-bu-qi wo."

I think, "You should not look down on me."

This indicates that the core concept of perspective conflict of Huang \& Liu's (2001) approach, which is intuitively on the right track, needs further refinements to rule out the long-distance construal of ziji in (43). Also, one may raise the question whether this perceptual concept could be formalized as a component of the syntactic computation. This is where the POV valuation mechanism comes in. I will demonstrate how to extend the formal POV valuation mechanism to the logophor ziji to capture (43) and the related data regarding the Blocking Effects induced by the first-/second-person embedded subject. In particular, I submit that the logophor ziji contains unvalued POV features $[u \mathrm{~d}, u \mathrm{a}]$ that need to be valued by the closest POV-op just like the $[u \mathrm{~d}]$ of daodi and causal zenme. Essentially, this POV valuation approach is similar to Huang \& Tang's (1991) formal approach to the Blocking Effects of ziji. However, it is not the agreement of $\phi$-features that derive the relevant facts, as claimed in their paper. Rather, it is the concepts of discourse participants and addresser that are governing the 
long-distance construal of $z_{i j i}{ }^{23}$ Before going into the detail of how this mechanism may explain (43), a discussion of the interaction of ziji and daodil causal zenme is necessary.

Given the valuation relation between the unvalued POV features of the logophor ziji and the POV-op, one may expect that the logophor ziji is incompatible with daodi/causal zenme just like the case for the illicit combination of daodi and causal zenme within one interrogative. However, this prediction is not borne out:
a. Zhangsan ${ }_{i}$ xiang-zhidao [ Lisi $_{j}$ daodi weishenme taoyen $\left.\mathbf{z i j i} \mathbf{i}_{\mathbf{i} / \mathbf{j}}\right]$. Zhangsan wonder Lisi THE-HELL why hate self 'Zhangsan ${ }_{i}$ wonders why the hell Lisi ${ }_{j}$ hates him $/$ himself $_{j}$ '. Zhangsan wonder Lisi how-come would hate self 'Zhangsan ${ }_{\mathrm{i}}$ wonders how come Lisi $\mathrm{j}_{\mathrm{j}}$ would hate him /himself $_{\mathrm{j}}$.'
b. Zhangsan ${ }_{i}$ xiang-zhidao [Lisi $\mathbf{j}_{\mathbf{j}}$ zenme hui taoyen $\mathbf{z i j i}_{\mathbf{i} / \mathbf{j}}$ ].

This problem may be settled by the additional assumption that there is a POV-op at the edge of each phase (i.e., CP and v*P; cf. Chomsky 2000, 2001) when a phase contains one item with unvalued POV features. ${ }^{24} \mathrm{As}$ a result, the unvalued POV features of daodi/causal zenme and the logophor ziji in (44) are valued by the POV-op at the $\mathrm{CP}$ phase edge and the $\mathrm{V} * \mathrm{P}$ phase edge, respectively. The valuations proceed within two different phases, not interfering with each other; therefore, the co-occurrence of daodi/causal zenme and ziji is allowed.

Now we can examine how the POV valuation mechanism deals with the longdistance construal of ziji. The relevant derivations related to the POV valuation in (40) are as in (45).

\footnotetext{
${ }^{23}$ The assumption that subject NPs agree with the embedded POV-op, and the POV feature in daodi, causal zenme, and logophoric ziji in terms of $[ \pm \mathrm{d}, \pm \mathrm{a}]$ features in MC suggests that the $[ \pm \mathrm{d}, \pm \mathrm{a}]$ features may be the default setting of $\phi$-features in a language without overt morphological manifestation of such features. It is possible that the fine-grained distinction of $\varphi$-features in terms of person, number, and gender features is available only when there is overt morphological evidence for the language learner. This issue is beyond the scope of the current paper, but see Miyagawa 2010 (pp. 150, fn.11) for a similar view on this issue.
}

${ }^{24}$ One piece of evidence for this comes from the interpretation of (i).

(i) Fortunately the Yankees unfortunately lost this game.

This sentence may be uttered by a Red Sox baseball fan who thinks that it is fortunate that the Yankees lost this game, a result that may benefit the Red Sox. On the other hand, the players of the Yankees take this as an unfortunate event. Therefore, the CP-level evaluative adverb fortunately is uttered from the external speaker's point of view, while the $\mathrm{V} * \mathrm{P}$-adjoined unfortunately is evaluated from the matrix subject's point of view, presumably licensed by the POV-op at the CP-phase level and the $\mathrm{V} * \mathrm{P}$-phase level, respectively. 
(45)

Zhangsan $_{i}$ renwei $\left[\right.$ Lisi $_{j}$ kan-bu-qi $\left.\mathbf{z i j i}_{\mathrm{i} / \mathrm{j}}\right]$.

Zhangsan think Lisi look-not-up self

'Zhangsan ${ }_{\mathrm{i}}$ thinks Lisi $\mathrm{j}_{\mathrm{j}}$ looks down on him $\mathrm{i}_{\mathrm{i}} /$ himself $_{\mathrm{j}}$ '

a. $\quad\left[v^{* \mathrm{P}} z i i_{[u \mathrm{~d}, u \mathrm{a}]}-\mathrm{POV}-\mathrm{op}[u \mathrm{~d}, u \mathrm{a}] \ldots t\right]$

b. Lisi...[ $\left.{ }_{\mathrm{v} * \mathrm{P}} z i i_{[-\mathrm{d},-\mathrm{a}]}-\mathrm{POV}-\mathrm{op}[-\mathrm{d},-\mathrm{a}] \ldots t\right]$

c. $\left[\mathrm{CP} z i j i_{[-\mathrm{d},-\mathrm{a}]}-\mathrm{POV}-\mathrm{op}\right.$ Lisi...[v*P $t$-POV-op $\left.\left.[-\mathrm{d},-\mathrm{a}] \ldots t\right]\right]$

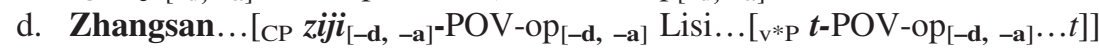

First, I follow Huang \& Liu's (2001) analysis of the LF movement of ziji for creating a direct input for the semantics of attitude de se expressed by ziji (cf. Huang \& Tang 1991 for the LF movement of ziji; Chierchia 1989 for the semantics of attitude de se). The only difference here is that the movement adjoins first to the intermediate vP-phase POV-op for successive cyclicity as shown in (45a). Second, note that at the stage (45a) the POV features (i.e., the logophoric orientation) of the $\mathrm{v}^{*} \mathrm{P}-$ phase POVop and ziji are indeterminate. Third, the logophoric orientation of both ziji and the $\mathrm{V}^{*} \mathrm{P}$-phase POV-op is valued by the embedded subject Lisi as $[-\mathrm{d},-\mathrm{a}]$ in $(45 \mathrm{~b})$. Fourth, the movement of ziji to the embedded CP-phase POV-op in (45c) is for creating the input for attitude de se. Finally, the POV features of the embedded CPphase POV-op are valued as [-d, -a] by the matrix subject Zhangsan in (45d), and the long-distance construal of the logophor ziji is allowed precisely because ziji and the embedded CP POV-op share the same POV features $[-d,-a]$.

The Blocking Effects emerge when ziji and the embedded CP phase POV-op do not share the same POV features, as shown in (46) and (47). The POV features of ziji are valued by the embedded subject in (46a) and (47a), respectively. However, the POV features of ziji are not consistent with those of the embedded CP-phase POV-op where $z i j i$ moves to create the input for attitude de se as shown in (46b) and (47b). The longdistance construal of the logophor ziji is thus blocked by this clash of POV features.

(46) Zhangsan $_{\mathrm{i}}$ renwei [wo $\mathbf{w o}_{\mathbf{j}}$ kan-bu-qi $\left.\mathbf{z i j i}_{\mathbf{j}} / *_{\mathrm{i}}\right]$.

Zhangsan think I look-not-up self

'Zhangsan ${ }_{\mathrm{i}}$ thinks $\mathrm{I}_{\mathrm{j}}$ look down on ${ }^{*} \mathrm{him}_{\mathrm{i}} /$ myself $_{\mathrm{j}}$ ',

a. $\quad$ wo...[ [v*P $\left.z i j i_{[+d,+a]}-P O V-o p_{[+d,+a]} \ldots t\right]$

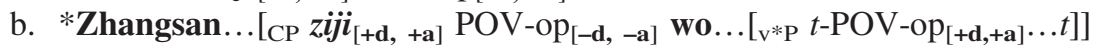

(47) Zhangsan ${ }_{i}$ renwei $\left[\mathbf{n i}_{\mathbf{j}}\right.$ kan-bu-qi $\mathbf{z i j i}_{\mathbf{j}}$; $\left._{\mathbf{i}}\right]$.

Zhangsan think you look-not-up self

'Zhangsan thinks you $_{\mathrm{j}}$ look down on *him /yourself $_{\mathrm{j}}$.'

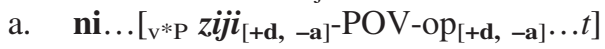

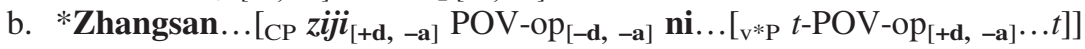

As for (43a) where Huang \& Liu's pragmatic account gives the wrong prediction, the proposed mechanism correctly rules out the long-distance construal of ziji in this case because of the conflict of POV features between ziji and the CP-phase level POV-op, as shown in (48). 
(48) $\mathrm{Wo}_{\mathrm{i}}$ renwei $\left[\mathrm{ni}_{\mathrm{j}}\right.$ bu yinggai kan-bu-qi $\left.\mathbf{z i j i}_{*_{\mathrm{i}} \mathrm{j}}\right]$.

I think you not should look-not-up self

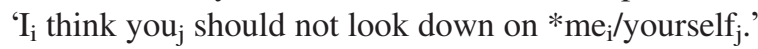

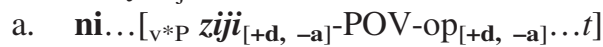

b. $* \mathbf{W o} \ldots\left[{ }_{\mathrm{CP}} \mathbf{z i j i}_{[+\mathbf{d},-\mathbf{a}]}-\mathrm{POV}-\mathrm{op}_{[+\mathbf{d},+\mathbf{a}]} \mathbf{n i} \ldots\left[\mathrm{v}^{* \mathrm{P}} t-\mathrm{POV}-\mathrm{op}[+\mathbf{d},-\mathbf{a}] \ldots t\right]\right]$

In this subsection, I demonstrated how the POV valuation mechanism may explain not only the case where Huang \& Liu's (2001) analysis makes a wrong prediction, but also the blocking of the long-distance construal induced by a first-/second-person local antecedent of ziji. Nevertheless, the extent to which this mechanism captures all other properties of the logophor ziji remains to be seen, and I leave this for future studies.

\section{Comparison with den Dikken \& Giannakidou (2002)}

Den Dikken and Giannakidou (2002) propose a comprehensive analysis of wh-thehell phrases in English as dependent polarity items, which need to be licensed by a c-commanding nonveridical operator such as the question operator and negation. However, it is not clear how this licensing condition could rule out the combination of daodi 'the hell' and causal zenme 'how come' in MC. More specifically, even if we combine den Dikken \& Giannakidou's polarity-licensing analysis with Fitzpatrick's (2005) proposal that how come selects a factive complementizer $\mathrm{C}_{\mathrm{FACT}}$ that creates a factive island (cf. Melvold 1991) as in the structure (49), the result does not provide an explanation for the illicit combination of daodi and causal zenme, given that the licensing force of the nonveridical operator is not overridden by the $\mathrm{C}_{\mathrm{FACT}}$ that is lower in the structure.

(49) Nonveridical operator...daodi...zenme $\mathrm{C}_{\mathrm{FACT}} \ldots$

Further, the licensing environments of wh-the-hell phrases noted by den Dikken \& Giannakidou apply to how come as well, as evidenced by (50) and (51). One may also treat how come as a dependent polarity item based on this parallelism of licensing environments.

(50) a. I *(don't) know who the hell would buy that book.

b. He $*$ (didn't) $\{$ told me/confirmed/realized $\}$ who the hell had spread those horrible rumors about me.

(51) a. I ??(don't) know how come John did not show up yesterday.

b. He ??(didn't) \{told me/confirmed/realized $\}$ how come John did not show up yesterday.

However, the licensing condition of dependent polarity items is itself insufficient to rule out the combination of how come and the hell. This is because although it is 
possible to put two polarity items in one licensing environment as in (52a) and (52b), $(52 \mathrm{c})$ is still ill-formed.

(52) a. I don't know [who the hell would read any of the books].

b. I don't know [how come anyone would spread bad rumors about me].

c. *I don't know [how come the hell John did not come to class yesterday].

Thus, to account for the incompatibility problem, a polarity approach to wh-the-hell, although perhaps necessary, should also take the logophoric negative attitude of daodi and causal zenme into consideration.

\section{Summary}

Recapitulating the results reached in this paper, the negative attitudes conveyed by daodi and causal zenme need to be ascribed to either the external speaker or the internal speaker (the subject referent of certain speech-act verbs) to obtain the full interpretation of an attitude-bearing question. This can be formalized as their unvalued POV feature $[u \mathrm{~d}]$ that must be valued by a POV-op for determination of their logophopric orientation and the identification of their attitude-bearer. The minimality condition of this valuation relation prevents daodi from co-occurring with causal zenme under the same question operator because only the POV feature of daodi may be valued in such a configuration, leaving the POV feature of zenme unvalued. Further, the matrix-subject person-feature constraint is derived from the requirement that daodi's POV feature obtained from its closest POV-op must be consistent with that of the POV-op at its scope position. Additionally, adopting the POV valuation mechanism makes it possible to formalize the Blocking Effects of ziji induced by the first-/second-person embedded subject. More generally, the analysis here, if on the right track, suggests that syntactic computation plays a role in determining pragmatic licensing and contributes to our understanding of the syntaxpragmatics interface.

\section{References}

Chierchia, G. 1989. Anaphora and attitudes de se. In Semantics and contextual expression, ed. R. Bartsch, J. van Benthem \& P. van Emde Boas, 1-31. Dordrecht: Foris.

Chomsky, N. 1982. Some concepts and consequences of the theory of government and binding. Cambridge, MA: MIT Press.

Chomsky, N. 1986. Barriers. Cambridge, MA: MIT Press.

Chomsky, N. 2000. Minimalist inquiries: The framework. In Step by step: Essays on minimalism in honor of Howard Lasnik, ed. R. Martin, D. Michaels \& J. Uriagereka, 89-155. Cambridge, MA: MIT Press.

Chomsky, N. 2001. Derivation by phase. In Ken Hale: A life in language, ed. M. Kenstowicz, 1-52. Cambridge, MA: MIT Press.

Cinque, G. 1999. Adverbs and functional heads. Oxford: Oxford University Press.

Collins, C. 1991. Why and how come. In More papers on wh-movement (MIT Working Papers in Linguistics 15), ed. L. L.-S. Cheng \& H. Demirdache, 31-45. Cambridge, MA: MITWPL. 
den Dikken, M. \& A. Giannakidou. 2002. From hell to polarity: "Aggressively non-D-linked" wh-phrases as polarity items. Linguistic Inquiry 33:31-61.

Fitzpatrick, J. 2005. The whys and how comes of presupposition and NPI licensing in questions. In Proceedings of the 24th West Coast Conference on Formal Linguistics, ed. J. Alderete, C.-H. Han \& A. Kochetov, 138-145. Somerville, MA: Cascadilla Proceedings Project.

Harley, H. \& E. Ritter. 2002. Person and number in pronouns: A feature-geometric analysis. Language 78:482-526.

Huang, C.-T. J. 1982. The logical relations of Chinese and the theory of grammar. Ph.D. dissertation, MIT, Cambridge, MA.

Huang, C.-T. J., Y.-H. Huang, T.-H. Teng \& R. Tiedeman. 1984. Reflexives in Chinese and the teaching of Chinese. In Proceedings of the 1st World Conference on Chinese Language, 205-215.

Huang, C.-T. J., Y.-H. A. Li \& Y. Li. 2009. The syntax of Chinese. Cambridge: Cambridge University Press.

Huang, C.-T. J. \& C.-S. L. Liu. 2001. Logophoricity, attitudes, and ziji at the interface. In Long-distance reflexives (Syntax and Semantics 33), ed. P. Cole, G. Hermon \& C.-T. J. Huang, 141-195. San Diego, CA: Academic Press.

Huang, C.-T. J. \& M. Ochi. 2004. Syntax of the hell: Two types of dependencies. In Proceedings of NELS 34, ed. K. Moulton \& M. Wolf, 279-294. Amherst, MA: GLSA Publications.

Huang, C.-T. J. \& C.-C. J. Tang. 1991. The local nature of the long-distance reflexives in Chinese. In Long-distance anaphor, ed. J. Koster \& E. Reuland, 263-282. Cambridge: Cambridge University Press.

Huang, Y.-H. 1984. Chinese reflexives. In Studies in English literature and linguistics 10:163188. National Taiwan Normal University, Taipei.

Kuo, C.-M. 1996. The interaction between daodi and wh-phrases in Mandarin Chinese. Ms., University of Southern California, Los Angeles.

Lasnik, H. \& M. Saito. 1984. On the nature of proper government. Linguistic Inquiry 15:235289.

Lasnik, H. \& M. Saito. 1992. Move $\alpha$ : Conditions on its application and output. Cambridge, MA: MIT Press.

Melvold, J. 1991. Factivity and definiteness. In More papers on wh-movement (MIT Working Papers in Linguistics 15), ed. L. L.-S. Cheng \& H. Demirdache, 97-117. Cambridge, MA: MITWPL.

Pires, A. \& H. L. Taylor. 2007. The syntax of wh-in-situ and common ground. In Proceedings of the 43rd annual meeting of the Chicago Linguistic Society, ed. M. Elliot, J. Kirby, O. Sawada, E. Staraki \& S. Yoon, 201-215. Chicago: Chicago Linguistic Society.

Sells, P. 1987. Aspects of logophoricity. Lingustic Inquiry 18:445-479.

Speas, M. 2004. Evidentiality, logophoricity, and the syntactic representation of pragmatic features. Lingua 114:255-276.

Tenny, C. 2006. Evidentiality, experiencers, and the syntax of sentience in Japanese. Journal of East Asian Linguistics 15:245-288.

Speas, M. \& C. Tenny. 2003. Configurational properties of point of view roles. In Asymmetry in grammar: Vol. 1: Syntax and semantics, ed. A. M. Di Sciullo, 315-343. Amsterdam: John Benjamins.

Tsai, W.-T. D. 1994. On economizing the theory of A-bar dependencies. Ph.D. dissertation, MIT, Cambridge, MA.

Tsai, W.-T. D. 2004. Left periphery and how-why alternations. Ms., National Tsing Hua University, Taiwan. 


\section{Chao-Ting Tim Chou}

Xu, L. 1993. The long-distance binding of ziji. Journal of Chinese Linguistics 21:123-141.

Chao-Ting Tim Chou

University of Michigan

440 Lorch Hall

611 Tappan Street

Ann Arbor, MI 48109-1220

USA

ctchou@umich.edu 